Robert M.

La Follette School of Public Affairs

at the University of Wisconsin-Madison

Working Paper Series

La Follette School Working Paper No. 2005-022

http://www.lafollette.wisc.edu/publications/workingpapers

\title{
Crisis Management Policy and Hierarchical Networks
}

\section{Donald P. Moynihan}

La Follette School of Public Affairs, University of Wisconsin-Madison

dmoynihan@lafollette.wisc.edu

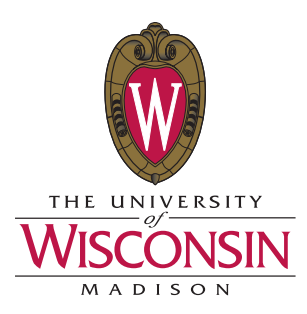

Robert M. La Follette School of Public Affairs

1225 Observatory Drive, Madison, Wisconsin 53706

Phone: 608.262.3581 / Fax: 608.265-3233

info@lafollette.wisc.edu / http://www.lafollette.wisc.edu

The La Follette School takes no stand on policy issues; opinions expressed within these papers reflect the views of individual researchers and authors. 


\title{
Crisis Management Policy and Hierarchical Networks
}

\author{
Donald P. Moynihan \\ Assistant Professor of Public Affairs \\ The Robert M. La Follette School of Public Affairs \\ University of Wisconsin-Madison \\ Email comments or questions to: dmoynihan@lafollette.wisc.edu
}

September 20, 2005 


\title{
Crisis Management Policy and Hierarchical Networks
}

\begin{abstract}
The contemporary public management literature portrays a world where the traditional functions of government are increasingly being coordinated by networks rather than hierarchies. Networks have particular characteristics that make them distinct from hierarchies and provide them with operational advantages. This paper suggests that in crisis situations a combination of the virtues of both networks and hierarchies are required. For most types of complex emergencies a network is necessary, because no single organization can comprehensively meet the challenge. However, the actors in this network must coordinate to act quickly, collectively and decisively, traits not normally associated with newly-created networks. The solution practiced in crisis management is to overlay a hierarchical structure on the network of actors involved. Network characteristics such as mutual trust remain important for the success of the response, but the actors find themselves operating within a clear chain of command that emphasizes authority and standard operating procedures. I illustrate the operation of one of these hierarchical networks in dealing with an exotic animal disease outbreak in California.
\end{abstract}




\section{Introduction: The Crisis Network Paradox}

To paraphrase Norton Long, the lifeblood of hierarchies is authority. ${ }^{\mathrm{i}}$ A similar truism for networks would probably be that the lifeblood of networks is trust. The two choices, hierarchy or network, seem like stark alternatives in the delivery of public services. Indeed, definitions of networks almost inevitably contrast them with hierarchies, suggesting that networks have distinct management characteristics and different challenges.

The concept and study of networks is now advanced enough that we may explore exceptions to the ideal-type of networks. This paper proposes that hierarchies and networks do not necessarily represent two ends of a continuum. In certain situations elements of each method of social coordination are required. I refer to this approach as hierarchical networks. A hierarchical network uses hierarchical control and rules to help manage a network of multiple organizations.

One policy area challenges the idea that networks and hierarchies are distinct. Crisis management policy has received an extraordinary level of political attention in the aftermath of 9/11, and the creation of the Department of Homeland Security (DHS) (Moynihan, 2005a). In 2004, in response to Homeland Security Presidential Directive-5, Management of Domestic Incidents (Feb. 28, 2003), the DHS released two closely related policy statements intended to shape the response to what were termed as "incidents of national significance." The National Incident Management System (NIMS) (DHS, 2004a) and the National Response Plan (DHS, 2004b) represent “profoundly significant changes” (Falkenrath, 2005, 132) in national crisis management policy, seeking to eliminate ambiguity between how crises were defined and who was responsible for them. The documents merged the concepts of crisis management (previously regarded as a law enforcement function tasked to the agencies within the Department of Justice) and consequence management (the responsibility of the Federal Emergency Management 
Agency (FEMA)) into the single concept of incident management, and identified the DHS as the primary federal responder.

In crisis response, to a greater degree than most policy areas, policy is management. The DHS policy pronouncements, particularly the NIMS, read like a management textbook. Although the term hierarchical network is not used, the concept is central to the policy directive. NIMS accepts that multiple organizations from different levels of government and the private and non-profit sectors will work together to deal with emergencies. Networks are the default assumption for the types of emergencies that NIMS addresses. However, NIMS also assumes that such networks need to be centrally coordinated and capable of rapid response.

We therefore have a crisis network paradox. Crisis networks face situations that no single organization can deal with, but require the characteristics unusual to networks: rapid and decisive action. In seeking to solve this paradox, DHS policy statements promoted a mixture of hierarchical and network structures.

Can hierarchical and network principles be melded together? This topic is important, since an affirmative answer suggests that portrayal of stark differences between hierarchies and networks is the result of overstated ideal types, and that social forms or coordination can usefully exist between these two types. The subject is also important because it is at the heart of the national crisis response policy. Management failures in this area (as the initial response to Hurricane Katrina appears to have been) are costly in terms of lives and economic losses, and influence the credibility of DHS policies.

This paper proposes and examines the concept of the hierarchical network. The next section examines the basic characteristics of networks, and how complex emergencies demand a response that involves a mixture of the two ideal types. The following section looks at how 
national policy in the area of crisis management directs the creation of hierarchical networks.

Then I examine hierarchical networks in practice, using case evidence from a taskforce applying these principles as it sought to eliminate an exotic chicken disease in California and other western states during 2002-2003. I examine the hierarchical aspects of the taskforce in the case, before examining the importance of network characteristics - particularly trust - in helping the taskforce succeed.

\section{Networks and Hierarchies as Ideal Types}

The network concept is usually defined and explained in terms of its contrast with hierarchies within single organizations. For example, O' Toole $(1997,45)$ defines networks as "structures of interdependence involving multiple organizations or parts thereof, where one unit is not merely the formal subordinate of the others in some larger hierarchical arrangement.” According to Alter and Hage (1992, 78), a basic normative characteristic common to all networks is that they are not hierarchical, and rely on lateral linkages and self-regulation. Alter and Hage $(1992,201)$ further hypothesize that to the extent if networks have strong bureaucratic characteristics (more centralized, large, complex and differentiated), performance will be lower. Indeed, networks are praised as an alternative to traditional hierarchies that are bound in red tape (Goldsmith and Eggers, 2004).

Powell (1990) argues forcefully that networks are an approach to social coordination that is distinct from markets and hierarchies. According to Powell, networks are not only characterized by multiple organizational members, but also by particular management characteristics.

Networks rely on the complementary strengths of members, whereas hierarchies are organized via employment relationship. Hierarchies rely on routines to communicate, whereas networks 
rely on relational form of communication. Networks are more flexible than hierarchies, but have a similar level of employee commitment as hierarchies. The climate in hierarchies is formal and bureaucratic, while in networks it is characterized by mutual benefits and openeneded relationships. Interorganizational relationships are more likely to occur among partners with relative equity in power, in contrast to the dependence of hierarchical actors on more senior levels of authority (Brass et al, 2001).

A critical characteristic of networks is the means by which members cooperate, and avoid and resolve conflict. In hierarchies, conflicts are resolved via administrative fiat or supervisory authority, while in networks norms of reciprocity and a concern for long-term reputation fosters cooperation (Powell, 1990). Network actors increase relational trust by using information on prior interactions to establish perceptions of reliability (Brass et al., 2004). Reciprocity norms are therefore central to shaping the behavior of network actors. Such norms are more likely to occur when actors can communicate before decisions are made, learn reciprocity norms and can punish those who deviate from those norms (Ostrom, 1998). Non-cooperative behavior by one network actor will be noted by others, prioritizing the need to maintain a positive long-term reputation. A requisite amount of time is necessary to allow multiple interactions to take place, allowing norms of reciprocity to give way to the establishment of reputations and mutual trust.

Not only are the management characteristics of networks different, but the management capacities required for networks are also argued to be distinct from those of hierarchies (Agranoff and McGuire, 2001.) According to Joop and Klijn (2004): "The role of the network manager is one of mediator and stimulator of interaction and not one of central director." Social capital and trust, shared learning, and a culture of joint problem solving characterize collaboration (Bardach, 1998). For members, networks are a "psychological reality" (Bardach, 
2001, 152) in that they perceive themselves and others as members pursuing common goals. But membership in networks is generally assumed to be voluntary, and consensus is essential to continuity. This reliance on voluntary cooperation makes networks are a less stable forms of social actions than hierarchies (Milward and Provan 2000).

\section{A Contrarian View: Can Networks and Hierarchies be Combined?}

Networks are increasingly central to the study of public management. It is difficult to think of a policy area where networks are not involved in service delivery. The basic assumptions about networks outlined above, though initially developed by scholars outside of public management and largely drawn from private-sector examples, have been largely accepted in the public management literature. McGuire (2003, 1-2) notes, “(s)lowly but surely, while the novelty of network research in the public management field wears off, the claim of 'network management is different' is becoming the standard refrain and is now accepted as the popular wisdom." McGuire suggests that the "difference" perspective is at best overstated, and may be inhibiting the search for knowledge about network management in the public sector.

An additional challenge to the idea of stark differences between networks and hierarchies comes from the work of Milward and Provan (2000). They find that networks in the area of mental health tend to actually work better when there is a dominant central actor that directs the network. They suggest that the use of principal-agent relationships, typically found in markets or hierarchies, will improve services in networks. A powerful agency is in a strong position to exert the position of principal over other members of the network, and are more easily held accountable than the collective of network members. 
The potential for a strong central actor appears particularly likely in public sector networks, where all participants are not created equal. In a public network, there is likely to be an organizational actor that is the gatekeeper of public funds, and is therefore able to exert coercive power over the recipient of these funds, often formulated in terms of a contract. As McGuire (2003) points out, government is not just another actor in the network, but the steerer, the resource holder, the actor with democratic legitimacy, and the subject of political accountability. Milward and Provan (2000) also find that stability fosters the effectiveness of networks, allowing for coordination, the building of trust, and the ability to work out problems among a stable set of actors: "Stability of a system is both a strength and a weakness. The key is to find a balance between flexibility and rigidity” (Milward and Provan, 2000, 373). A related argument by O’Toole and Meier (1999) is that hierarchies are better designed to buffer environmental shocks and provide a measure of stability than networks. Taken together, these arguments suggest that among networks that lack stability, introducing aspects of hierarchical management will improve performance.

The particular contexts and challenges of crises - high consequences, limited time, high uncertainty and ambiguity, infrequent yet politically salient - create an incentive to imbue the network with traits of an action-oriented hierarchy: responsive, stable, rapid, decisive, with clear direction, and shared understanding of processes and solutions (Moynihan and Herd, 2005). The nature of crises therefore prompts policymakers such as the DHS to replace many of the characteristics of networks (voluntary cooperation, decisions slowed by the need for consensus, a reliance on reciprocity norms, and conflicting goals among members) with hierarchical characteristics. 


\section{Hierarchical Networks in Crisis Response Policy}

The mixing of network and hierarchical forms has become a matter of formal policy in crisis management. Some emergencies are frequent and predictable enough that it makes sense to have an organization that specializes in dealing with them, e.g. forest fires, health emergencies. However, other emergencies are asymmetrical, occurring with such infrequency, unpredictability and scale that it is not possible for any single organization to respond to them. They require a network of responders. Such crises include any incidents of national significance, such as bioterror or nuclear threats, or natural ultra-catastrophes such as Hurricane Katrina.

Planning for asymmetrical emergencies is the job of the Department of Homeland Security (DHS). NIMS offers national standards and principles for organizing in response to crises. NIMS assumes that any major incident will require a network of responders from different levels of government, as well as from the private and non-profit sectors, and that such networks can be best managed with hierarchical layers of authority. Command and control comes in the form of the Incident Command System (ICS). ${ }^{\mathrm{ii}}$ The ICS is a hierarchical mode of organizing critical management systems needed in an emergency: planning, operations, logistics, and administration/finance. Each function reports to a single incident commander who has decisionmaking power for the ICS. If the geographic spread of the emergency requires multiple incident commands, incident commanders report to a single area commander. Figure 1 illustrates the logic of the ICS.

Insert figure 1 here: ICS model 
NIMS has already proven relevant to practitioners. All federal agencies are required to use ICS, and organizations such as Federal Crisis Management Agency and the U.S. Department of Agriculture (USDA) have focused on training its principles to workers. State and local responders are encouraged to adopt the ICS requirements in order to receive federal preparedness grants.

While NIMS concedes that the ICS may need to be adapted to particular situations, it is intended to push emergency responders to learn, accept, and use a hierarchical structure rather than developing a structural design of their own choosing. The ICS essentially imposes a hierarchical structure on a network. Authority and control are at the top. The positions of incident commanders and area commanders in the ICS model make clear who they key decisionmakers are. The chain of command is intended to ensure that all workers have an identified supervisor, each supervisor has a manageable span of control, and that lower-level actors follow orders.

NIMS places a particularly strong emphasis on the need for different actors to operate under a unified command. A unified command "overcomes much of the inefficiency and duplication of effort that can occur when agencies of different functional and geographic jurisdictions, or agencies at different levels of government, operate without a common system or organizational framework" (DHS, 2004a, 14). In the following list of proposed advantages of a unified command, we see a strong harkening to hierarchical principles (DHS, 2004a, 15):

- A single set of objectives is developed for the entire incident

- A collective approach is used to develop strategies to achieve incident objectives

- Information flow and coordination is improved between all jurisdictions and agencies involved in the incident 
- All agencies with responsibility for the incident have an understanding of joint priorities and restrictions

- No agency's legal authorities will be compromised or neglected

- The combined efforts of all agencies are optimized as they perform their respective assignments under a single Incident Action Plan

The ICS also reflects network values, though to a lesser degree. It recognizes the need for multiple organizations to deal with most emergencies, but reflects a concern that those agencies must be managed. Participants are urged to collaborate in the setting of goals. The ICS is intended to offer the flexibility of networks by avoiding some of the procedural limitations of home agencies, by creating an entity that has the ability to access resources without the traditional and lengthy budget justification process, and avoids procedural red tape due to emergency powers, e.g. hire of temporary employees.

\section{A Hierarchical Network in Practice: Exotic Newcastle Disease in California}

The ICS model argues for an intriguing mixture of hierarchical and network principles, but can it work in practice? To answer this question, I present case evidence on the outbreak and eventual containment of Exotic Newcastle Disease (END) in the State of California. END is a highly contagious and generally fatal disease in poultry. It has the potential to cripple a poultry industry; the discovery of END in California prompted trade bans of poultry by major export markets. The estimated impact of the trade restrictions arising from the outbreak was $\$ 167$ million. The estimated weekly impact of indirect costs (loss of tourism, increased retail prices 
for the affected product, decreased consumer demand, more stringent regulatory controls and increased cost of replacement stock) was \$226.86 million (Speers et al, 2004; Werge, 2004).

An outbreak of END in the State of California was confirmed on October 1, 2002, and subsequently spread to Arizona, Nevada, and Texas. Quarantines were also placed in Colorado and New Mexico. A taskforce was created to eradicate the disease, involving ten major state and federal agencies, including vets, forest-service officials, health and human service officials, highway patrol officers, lab technicians, environmental officials, and short-term hires. Appendix 1 details the different participants involved and their role on the taskforce. More than 7,000 workers rotated in and out of the taskforce, although the maximum taskforce size at any one time was approximately 2,500. Supervisors and managers were rotated in and out, usually for periods of three weeks, because of employee burnout and the needs of their home organization. This constant rotation created a good deal of discontinuity in the operations of the taskforce.

Once quarantines were established, taskforce teams visited private residences and commercial bird premises to diagnose whether an infection existed or was nearby. If there was a suspected case of END, the value of the birds was appraised, the birds were euthanized and premises were cleaned and disinfected. The taskforce found 932 infected premises.

Does the case represent a success story? Given that emergency responses like the END taskforce are usually unique, it is difficult to come up with a definitive benchmark for relative success, but the taskforce can point to evidence of effectiveness. One simple benchmark for success is achievement of task. The taskforce eliminated END and limited its impact on the poultry industry. By September 16, 2003, final quarantine restrictions related to END were removed. Alter and Hage (1992, 197-198) suggest that another measure of success is the perception of participants on whether the network has lived up to its potential: "Effectiveness in 
interorganizational systems is a perception among administrators and workers that their collective effort is achieving what it is intended to achieve, that it works smoothly, and that it is reasonably productive.” A common response from participants is that while there were initial problems in organizing to address the threat, the taskforce was ultimately well-managed and successful. The taskforce was also more successful in terms of time and costs than the nearest parallel, the response to a 1971 outbreak of END in California. The previous outbreak lasted from November 1971 to July 1974, a period of 33 months. The cost of the eradication effort was approximately \$250 million in 2003 dollars (\$56 million in 1972) and about 12 million birds were destroyed. This compares with an estimated cost of \$176 million for the 11-month outbreak in 2002-2003, where more than 4.5 million birds were killed. It is also worth noting that the taskforce had to deal with the additional complexity posed by detecting END among backyard flocks, particularly in Hispanic neighborhoods and among the illegal cockfighting community, whereas the previous outbreak was primarily limited to large commercial producers.

The case evidence comes from three major sources that provide detailed accounts of the outbreak. First, the Policy and Program and Development Unit of the Animal and Plant Health Inspection Service (APHIS) developed a 289-page After Action Review (Werge, 2004). Second, APHIS also undertook an outside review of the outbreak, leading to a four volume, 343-page series of reports by the CNA Corporation (Howell et al, 2004; Howell, 2004; Speers et al, 2004; Speers and Webb, 2004). Finally, the paper draws on interviews with a number of senior managers involved in the taskforce. More descriptive details on the case, the nature of END and the challenges facing the emergency taskforce can be found in Moynihan (2005b).

\section{Hierarchical Aspects of the Taskforce}


The clearest hierarchical aspects of the taskforce is the use of the ICS and efforts to standardize actions by establishing procedures. Figure 2 (from Howell, 2004, 34) provides the taskforce organizational structure, which is consistent with the basic ICS model and is hierarchical in nature.

\section{Insert figure 2 here}

The case demonstrated the benefits of the ICS model in dealing with exotic animal disease outbreaks, a type of emergency which had not used ICS frequently in the past. Many of the taskforce members, particularly the vets from Animal Plant and Health Inspection Service (APHIS part of the USDA) and Animal Health and Food Safety Services (AHFSS, part of California Department of Food and Agriculture (CDFA)), were not experienced with ICS, but concluded that it helped the taskforce succeed. Through the ICS, resources were divided, thousands of employees were moved around the country, organized into teams, given specific tasks on a daily or weekly basis and held accountable for their performance.

Incident commanders had to be able to make timely decisions, which in turn depended on the quality and timeliness of the information they received. The ICS depended upon a tasking system for incident response called the Emergency Management Response System (EMRS). The EMRS pulled together in near real-time relevant information about taskforce actions. This made the task of coordinating resources and activities much easier. A manager looking at the EMRS could tell whether a premises had been visited or not, and what actions had taken place or needed to occur (e.g., cleaning and disinfection, depopulation, appraisal status). It reduced the potential of personnel visiting the same premises twice, or reporting inconsistent information, 
and kept track of the location of personnel. The EMRS created a direct line of communication between front-line employees and incident commanders.

The use of information was consistent with a hierarchical approach. The EMRS was used for the purposes of control and direction by the center, not to facilitate self-organizing groups. While members of the organizations involved could access information easily, the goal of the area command was to use a wide array of information to develop a summary picture of overall progress and challenges at both the area and incident command level, and to simplify information into specific tasks for operational teams to accomplish. This process worked well once the technology for eliminating END was understood. Workers in the field did not have to engage in speculative "sensemaking” of their environment and role (Weick, 1995). ${ }^{\mathrm{iii}}$

\section{Unresolved Questions with ICS}

While the ICS was perceived as part of the taskforce's success, it left many questions for the taskforce members to resolve. The ICS is essentially a series of management principles and a structural design. It offers a standard model for how to manage crises, but does not describe specific management procedures and actions. It was left to taskforce participants to apply and adapt those principles as the response developed. Applying the ICS model is therefore closer to sculpting rather following a step-by-step assembly. Consistent with the observations of Bardach (1998), managers are craftsmen; the tools provided by the ICS are useful, but how to apply this tool depends a great deal on prior experience and the task requirements.

In sculpting the ICS, key questions are: Who is in charge? Who is placed in the boxes that make up the organizational design? The following section on trust provides the answer for the END taskforce (essentially, there was a joint command of federal and state officials), but each 
ICS will have to find its own answer to this question. Another key question is how the particular context of the incident demands that the ICS structure be adapted, if at all. In the END case those with veterinary expertise were the most likely to argue for adjustments with the ICS model to provide discretion to vets in the field, or the structural design of the ICS (for instance a commercial planning unit was established outside of the traditional ICS structure to coordinate directly with commercial producers). Forest service officials from the U.S. Forest Service (USFS) and the California Department of Forestry and Fire Protection (CDF) had significant experience with the ICS in other types of emergencies, and argued that the model did not need to be adapted.

\section{Standard Operating Procedures}

A basic challenge for the taskforce was to standardize its operations. Standard Operating Procedures (SOPs) are valuable because they provide structure, clarity, and knowledge that did not previously exist. This is something that both networks and hierarchies require, although as McGuire (2003) notes, they are rarely specified ahead of time for networks. SOPs define which issues in the network have been resolved and which all actors agree to follow. For the END outbreak, the degree of uncertainty associated with the disease, the size of the taskforce, the backyard aspect of the outbreak, and the degree of rotation increased the need for SOPs. Most employees were working in an unfamiliar area with unfamiliar colleagues as they tried to figure out the most effective way to battle the disease. SOPs not only provided some basic guarantee of standardization and accountability; they also helped individuals understand their role in the organization and what specific actions they were to take in a given situation. 
An exit survey of taskforce participants (Werge, 2004) found that the primary issues of concern were precisely the type of issues that hierarchies routinize in the form of management systems, i.e., personnel planning and administration, general organization, overall planning and internal communication, unclear lines of authority, lack of procedures for routine actions such as procurement. Network members wanted the taskforce to act more like a hierarchy with a single set of mature management systems. One lesson from the case is the need for crisis response taskforces to focus on creating the type of management routines taken for granted in organizations: tracking workers and other resources, reporting, communication, training on financial issues, recruiting, hiring and training, and contracting (Werge 2004).

Such processes have become so routine in hierarchies that reformers seek ways to reduce the degree of formalization or red tape associated with them. ${ }^{\text {iv }}$ But in crises SOPs establish managerial order where very little exists. The main challenge for employees in the taskforce was not a lack of flexibility, but a lack of stability. They needed to find answers to such basic questions as: What are my tasks? How am I to achieve them? What resources do I have? Who do I report to? How many days do I work? In the search for a balance between stability and flexibility, greater stability was a more pressing priority for the taskforce.

SOPs were sometimes straightforward, e.g., SOPs for cleaning and disinfecting. They were also sometimes controversial and indicative of the aggressive focus the taskforce maintained on eliminating the disease. An example of the latter was the requirement for depopulation of any birds (including pet birds) on any premises that were adjacent to or had an epidemiological link to an infected location (Speers et al, 2004, 13). As the taskforce continued, knowledge and procedures were formalized into an SOP manual that grew to over 400 pages. $^{\mathrm{v}}$ 
The development of SOPs reveals a consistent pattern. Initial disorganization and lack of coordination creates problems for the taskforce in doing its job. Such problems are observed and procedural solutions are suggested and become formalized. If needs be, the new procedure is further refined based on additional feedback. Cumulatively, such a pattern helps explain one of the widely-made observations taskforce members made. The taskforce was initially disorganized, but gradually became better at managing large numbers of individuals and tackling the disease. In part, this was due to the growing experience of taskforce members. SOPs were also important, both in codifying this experience and in transferring the knowledge to those new to the taskforce. One participant who joined the taskforce relatively late in the process was able to observe the benefits: "By the time I got there in April, everybody knew what they were doing. I mean, it had been pretty much if you were a part of survey crew you knew what your tasks were. If you were part of surveillance crew, you knew what your task was...by that time, those things were pretty well established so I don't think that there was a lot of question about what it is that I was supposed to do."

The development of SOPs was also tied to the growth of the taskforce, and the desire of taskforce leaders to exert control and consistency via rules when interpersonal communication could no longer be relied on. Dr. Annette Whiteford, the director of AHFSS, acted as an incident commander and as area commander of the taskforce, made the following comment:

In October, November and December, I was the incident commander and I was the one talking to the field folk and there was very little loss of message. In January and February, there was an area commander talking to incident commanders, who talked to section chiefs, who talked to various different units, so there was a little bit breakdown in communication... Again, every time you add a layer of communication, oral communication becomes less 
effective. It's the fastest and most efficient way to communicate effectively. Meetings and conference calls, you get immediate feedback, there is give and take, you are done and you are back in the field. However, when you add layers, oral communication becomes inefficient because you actually lose message."

Writing the SOPs during the outbreak took a good deal of time: additional preplanning for some predictable tasks might have reduced the initial disorganization. But as one manager pointed out, it is impossible to preplan all eventualities that might occur in an infrequent emergency incident, and SOPs will necessarily be written during the response:

SOPs are key for continuity. The problem was that we had SOPs that were a little bit dated for responding to END in a commercial setting that would be more appropriate for the central valley [in California] or Virginia. We really hadn't anticipated such a huge large-scale response in somewhere like the L.A. Basin. So we really had to rewrite all of our SOPs to a level of detail than never had existed before. So that was a huge effort and that's another lesson learned: early on in the response it is good to have a team of people dedicated to SOPs that are appropriate for that particular response. Now for fires, they have multiple fires every summer and it's not so hard for things like that, but for animal disease where you have to respond to a scare every 30 years, you need some kind of flexibility to write procedures during the response. You should preplan, they should be written out ahead of time, but no matter how good you preplanned, the actual response won't fit what you preplanned for.

\section{Network Aspects of the Taskforce}


The most obvious network element of the taskforce is the involvement of multiple organizations. These included private actors, most notably large-scale chicken producers, temporary workers and temp agencies. But the hub of the network was dominated by APHIS and AHFSS. While the federal level had some limited carrots and sticks it could use to induce cooperation with the state level, it did not have a classic hierarchical relationship, or even the leverage associated with inter-governmental grants for the case of END (although it did provide the bulk of fiscal resources). What fostered cooperation between the different levels of government was a trait we find in networks: shared interest in a common goal, i.e., stopping the spread of END.

This section focuses on another characteristic of networks: a reliance on trust. Trust in other actors inspires confidence, leads to delegation, and reduces transaction costs. Trust and cooperation builds up over multiple interactions, making time an essential factor. For emergency response teams, time is a luxury they cannot afford, particularly with the frequent rotation of staff. ${ }^{\mathrm{vi}}$ As long as crisis networks are characterized by limited duration and rotation of personnel, it is unrealistic to expect that trust will become the primary basis for action. So what role does trust play, if any, in crisis networks? This section seeks to make the following points:

- Hierarchical structures limit, but do not eliminate, the importance of trust as a means of coordination in the network.

- Trust can be fostered through a mission-driven culture, which an emergency situation lends itself to.

- Trust between network leaders is critical to the operation of the network, and leaders can model trust to network members.

- Previous interactions of network members fosters trust in the network. 
- The training and background of network members shapes the potential for trust in the network.

\section{Limiting, but not Eliminating, the Importance of Trust}

In networks, managers are characterized as mediators trying to develop consensus among voluntary actors (Agranoff and McGuire, 2001). The ICS structure and SOPs create a hierarchy within a network to reduce the need for voluntary agreement and consensus, and to offer guidance on who was to do what, how and when. The taskforce had a clear chain of command; actions were ordered, not requested. While managers in an ICS might have more hierarchical authority than managers in a network, it is important not to overstate this authority. Almost all employees are temporary in one way or another, and managers have little means of rewarding or punishing subordinates. Such carrots and sticks remain with the home organization, where the employees will return to.

According to END taskforce members, the absence of trust would have made operations more problematic. Even with the efforts to make the network more hierarchical and rule-driven, there were long periods when operations were in a flux, authority was unclear, and taskforce members were relying on members of other organizations to help them. Mutual trust was necessary in the taskforce, and was a feature its creation. When the taskforce was a relatively small group, there was a greater reliance on trust. As the taskforce grew, leaders relied increasingly on rules rather than trust to direct operations. Trust did exist in the taskforce, and helped coordination, but it coexisted with hierarchical modes of coordination.

The Role of Network Culture in Fostering Trust 
Actors who believe they are working toward shared goals are more likely to trust each other, but building cultures is as dependent on time as the creation of trust (Schein, 1992). ${ }^{\text {vii }}$ However, the importance of a task and intensity of working to meeting that task can speed the creation of a shared culture. Emergency situations lend themselves to the creation of a shared sense of mission and urgency. Members of the END taskforce understood the importance and immediacy of the mission, the consequences of failure, and that they shared this challenge with a team. Their working experience often included 12-hour days, seven-day weeks, working away from their family or a familiar environment, and completing difficult and often unpleasant tasks. The network culture that emerged was characterized by a focus on mission and task, demanding work, a sense of shared crisis, and esprit de corps. The following quotes from different members of the taskforce illustrate this point:

- Emergencies can be a very easy thing to manage because most people are so motivated to get the job done.

- Yes, there were individuals who maybe were not as productive as others, but by and large I saw, number one, an understanding that this was a serious incident and number two, a real commitment on the part of the organization and individuals to resolve it.

- The main thing I took away from this was that I was very pleased with how well these various different groups were able to work together. And I think part of it was that everyone recognized that we had a problem we had to resolve, and so we worked together and that was great. We didn't throw up barriers, we tried to take the barriers down and figure out ways we could work together.

- There is a sense of urgency. You are in these daily briefings. People who work for these state and federal agencies realize that these exotic diseases are something that are out of 
the ordinary. We know that the sooner we get our arms around it and get it stamped out, the better.

- So I think that there was this shared 'we all know this is hard, we're all away from home, long days, long hours' where people really are trying to do the best they can to get things done and work under those circumstances.

- I think that the other thing that worked in everybody's favor is that there was unity and everybody was there to eradicate this disease and so that helped work through some of the personality issues, some of the learning curves, that everybody just remained focused and committed to that.

The structural design of the ICS contributed to fostering a mission-driven culture. The taskforce was centered on managing a particular incident or mission - in this case, eliminating END - thereby making the concerns of the home organization secondary to the demands of the incident. One participant noted: "When you are using ICS, all those different agencies that come together are now really one agency responding to the incident. While they are working on that incident, their work is one, not as ten different agencies coming together and working as ten different agencies on the incident.” A sense of shared culture could therefore help to approximate the sense of a single organization, even though the taskforce lacked some of the basic attributes of most organizations, such as continuity of personnel, mature management systems, and lack of authority over most personnel decisions, e.g. pay and firing.

Culture is also shaped by leadership (Schein 1992). The leaders in this case furthered a sense of mission by applying the Management by Objectives (MBO) approach recommended by NIMS (DHS, 2004, 10). In daily and long-term planning, they established clear objectives and 
discussed progress toward these goals. These goals were reflected in the formal plans of the taskforce, and were directly related to tasks that front-line workers pursued, reducing the potential for goal displacement. The taskforce was a hierarchy, but it was a relatively flat one, meaning that the use of regular operational meetings, and the EMRS information and tasking system allowed for objectives to be pursued in the field rapidly after they were identified. According to Dr. Whiteford: "Probably the most important thing that the incident commander did, apart from managing people and handling personnel, was setting the priorities for the incident. So it’s MBO. You set the objectives for incident and then the different sections come together to meet those objectives.”

\section{The Role of Leadership and Prior Relationships in Fostering Trust}

Leadership was also critical to developing and modeling trust-based behavior to network members. Taskforce members did not talk much about the personal characteristics of leadership, but they did talk about the importance of consistency at the top of the taskforce (both in terms of message, but also in terms of having the same people in place), and the need for cooperation between senior members of different organizations. Some of the top positions were not subject to rotation, reducing the need to establish new relations when a member of the leadership team rotated out. Senior managers had the opportunity to develop relationships with other senior managers, while lower-level members were consistently dealing with the same leadership. ${ }^{\text {viii }}$

Interaction prior to the emergency is beneficial. During an emergency, participants will be largely focused on the task at hand; building interpersonal relationships will not be an immediate priority. The California mobilization plan for exotic diseases affecting livestock (CDFA, 2002, 9) suggests that, in cases like END, there is joint responsibility between the State Veterinarian 
from AHFSS (a state employee) and the Area Veterinarian in Charge (AVIC, a federal employee of the APHIS permanently based in California). The AVIC, Dr. Paul Ugstad, and his staff had strong positive relationships with the state veterinarian, Dr. Richard Breitmeyer, and his staff at AHFSS. Dr. Ugstad saw the preexisting relationship as "a huge advantage... If there were problems with the working relationships to start with, that might have been magnified with the emergency response situation. At the same time, I think the fact we have a good relationship might have been magnified by the emergency response." Dr. Mark Davidson, who worked as a Deputy Incident Commander in the taskforce, says, "There are definite advantages in that ongoing relationship because they work together on a routine basis on the management of day to day programs. So when you are thrown in the crisis mode you are in, they already have those established working relationships and don't have to develop them during the response."

Preplanning before emergencies can also foster interpersonal relationships and clarify roles. Dr. Ugstad put it this way: "Even if you deviate what you have put together in that plan, you still have gained a lot by going through that planning process, just by knowing who or what agency you need to be in touch with. You can spend an awful lot of time just trying to find out where do you go to get the answers to this. If you do an adequate amount of planning you can save a lot of time spinning your wheels trying to find out who to talk to."

The pattern of trust and cooperation between the AHFSS and APHIS created an expectation of partnership that is at odds with a hierarchy. Dr. Whiteford argues that, "Any animal disease disaster is federal and state from day one. It is not that the state resources get outstripped and then we ask the federal government for help. Day one, we are in collaboration." Indeed, the relationship between the two agencies was consistently organized as a partnership, employing a joint command with an area commander from each organization. This joint command structure 
was the most significant adaptation of the ICS, running contrary to the idea of clear command, and with a high potential for failure if the joint commanders issued mixed messages to staff. It worked chiefly because of trust between the leaders involved. The After Action Review mentions that: "In general, this joint command structure worked well to ensure that jurisdictional issues were coordinated, that State and Federal resources were jointly utilized, and that State and Federal employees worked together. The positive relations between the joint area commanders meant that the inevitable conflicts and differences of opinion were resolved and an example of cooperation was set for the entire task force." (Werge, 2004, 20). The following comments of network members support this point:

- The ability to work together as partners was very important.

- A lot of that [success in working together] was having the right personalities in the mix at the high levels. We all recognized that we needed to work together; otherwise, it was going to be a disaster. We figured out where we might disagree and we figured out how we could work around that, and it went well that way.

- The state Incident Commander and the federal Incident Commander made a commitment to work together and to be physically located together, and they did that pretty well. They didn't always agree on things but they stayed together, and just by spending time together over a period of weeks I think they were able to gain a level of trust in each other and see each other's perspective on things.

A focus group of managers (Werge, 2004) identified positive interagency relations as one of the success factors of the taskforce. In doing so, they identified the importance of leaders modeling cooperation and trust. Since the bulk of the USDA employees (which included both 
APHIS and USFS employees) were new to California, they took cues from more senior staff on working with state employees. The sharing of decisions among the joint command was useful in establishing basic norms of cooperation at lower levels. One taskforce participant notes: “The Area Commanders did a nice job of setting the tone for that. From the very beginning when I got there, if I drafted something, the first question out of the USDA Area Commander's mouth was 'Have you run this through the state folks? What do the state people think about this?' So I think they really set a nice tone of we're going to work this very cooperatively, and that's just the way it's going to be.,ix

One barrier to trust and source of conflict was the different disciplinary and organizational backgrounds between the actors involved. The participants brought into the taskforce the perspectives of their home agency or training, which often clashed with the perspectives of others. For instance, AHFSS and APHIS provided many vets to the taskforce, who placed a high value on the judgment and discretion of experts. Individuals coming from USFS and CDF were more used to paramilitary-style hierarchies and command and control in fighting fires. While participants from different backgrounds generally realized the value and skills of the other, they sometimes disagreed on questions of how to run the taskforce.

\section{Conclusion}

This paper has advanced the concept of hierarchical networks. In the area of crisis response, the utility of the concept appears self-evident. It closely fits with both the policy and practice of managing crises. Hierarchical networks suggest the possibility of mixing two ideal-types of social coordination, challenging the idea that networks and hierarchies (or our highly-stylized images of them) represent distinct choices. It is worth, therefore, considering whether the area of 
crisis management is the tip of the iceberg as far as hierarchical networks are concerned in the study of public organizations, or whether it is an atypical anomaly, the exception that proves the rule. Only further study can tell. It is clearly a topic that is important enough to merit study in its own right, as the response to Hurricane Katrina demonstrated. But the relevance of the concept of hierarchical networks depends a good deal on whether it exists outside of this environmental niche of management.

It is also worth investigating just how widely applicable the concept of hierarchical networks is within crisis management. The ICS originated in the 1960s as firefighters from different organizations in California sought to figure out ways to make it easier to coordinate with one another when fighting forest fires. The END case shows the ICS working under more challenging conditions, with a more heterogeneous set of actors who lacked of pre-existing relevant technological expertise. The ICS approach has also been used in high-profile emergencies such as the managing the attack on the Pentagon on 9/11, the response to anthrax attacks, the clean-up following the Columbia disaster, and the response to the Oklahoma City bombing (9/11 Commission Report, 2004; Gerbedering 2004; Cook, 2005).

But the DHS appeared to fail its most critical challenge since its inception and the creation of NIMS, the response to Hurricane Katrina. Does this represent a failure of hierarchical networks? There are two ways to interpret Katrina. The first is to argue that the differences in the Katrina case meant that a true hierarchical network ever formed. Most obviously, the system fragility of New Orleans to a hurricane was greater than the vulnerability of western states to a chicken disease (Comfort, 2002), and the scope of the disaster was much greater. State and local responders had close and trust-based relationships in the END case, something lacking in the Katrina response and strongly suggestive of the importance of trust in fostering cooperation and 
action. In the case of Katrina, the network of actors involved was much broader than in the END case, ranging all the way from individual volunteers who attempted to reach the disaster area to nation states offering their help. While the END taskforce could coordinate a relatively small and predominantly public taskforce over the course of a year, the ability to coordinate the much larger and more complex network of Katrina responders was most critical in the days prior to and following the disaster. Indeed, in both cases there was initial disorganization in the network response. With the END case, the taskforce could improve its organizational capacities before major consequences ensued, but small delays in responding to Katrina had a major negative impact.

While the criticism of the DHS and FEMA suggest a failure of hierarchies, the response to Katrina represents the failure of a command structure to coordinate network members. From this perspective, Katrina needed a hierarchical network as much as other crises, but it failed to emerge. Instead of a strong center coordinating network members, Katrina was met with what appeared to be a loosely-affiliated network of actors that failed to agree on who was in charge, and did not adequately communicate. The unresolved questions that the NIMS policy does not address (Who is in charge? What do they do?) paralyzed the response. As a result, timely efforts to help were sometimes stymied.

A second interpretation of the Katrina disaster is that the differences listed above represent critical contingencies on the application of hierarchical networks. This interpretation would examine the existing evidence on ICS and argue that it works best in non-catastrophic conditions i.e., crises on a smaller scale, allowing a moderate amount of time for the network to evolve, with smaller and more homogenous networks with strong preexisting ties. In the face of major catastrophes, where time is of the essence, the paradox of the crisis network returns: no major 
network can move as rapidly and decisively as the conditions demand. The ICS model might help, but does not replace the fundamental truth that such crises can ultimately only be coped with rather than managed.

Which interpretation is correct? The nature of the answer matters profoundly for crisis response policy, which will remain malleable in the years to come. The former interpretation suggests that the DHS should continue to argue that the ICS is a suitable template for all crises, and promote the understanding and application of hierarchical networks more vigorously. For ultra-catastrophes, this implies a stronger and more immediate federal involvement instead of waiting for federal and local capacities to be exhausted. Indeed, DHS Secretary Chertoff suggested that this was one of the lessons of Katrina (Lipton, Drew, Shane and Rohde, 2005). If the second, more pessimistic, interpretation is correct, then the basic response policies promoted by the DHS only apply to certain crises, and not to the most catastrophic. This implies the need for a major policy overhaul in crisis response. 
Figure 1: The Basic Structure of the Incident Command System

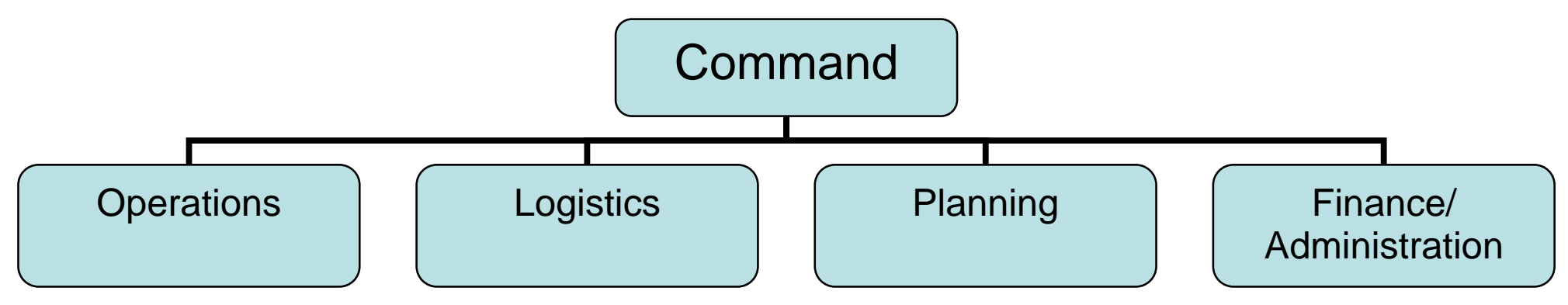


Figure 2: Organizational Structure of the END Taskforce

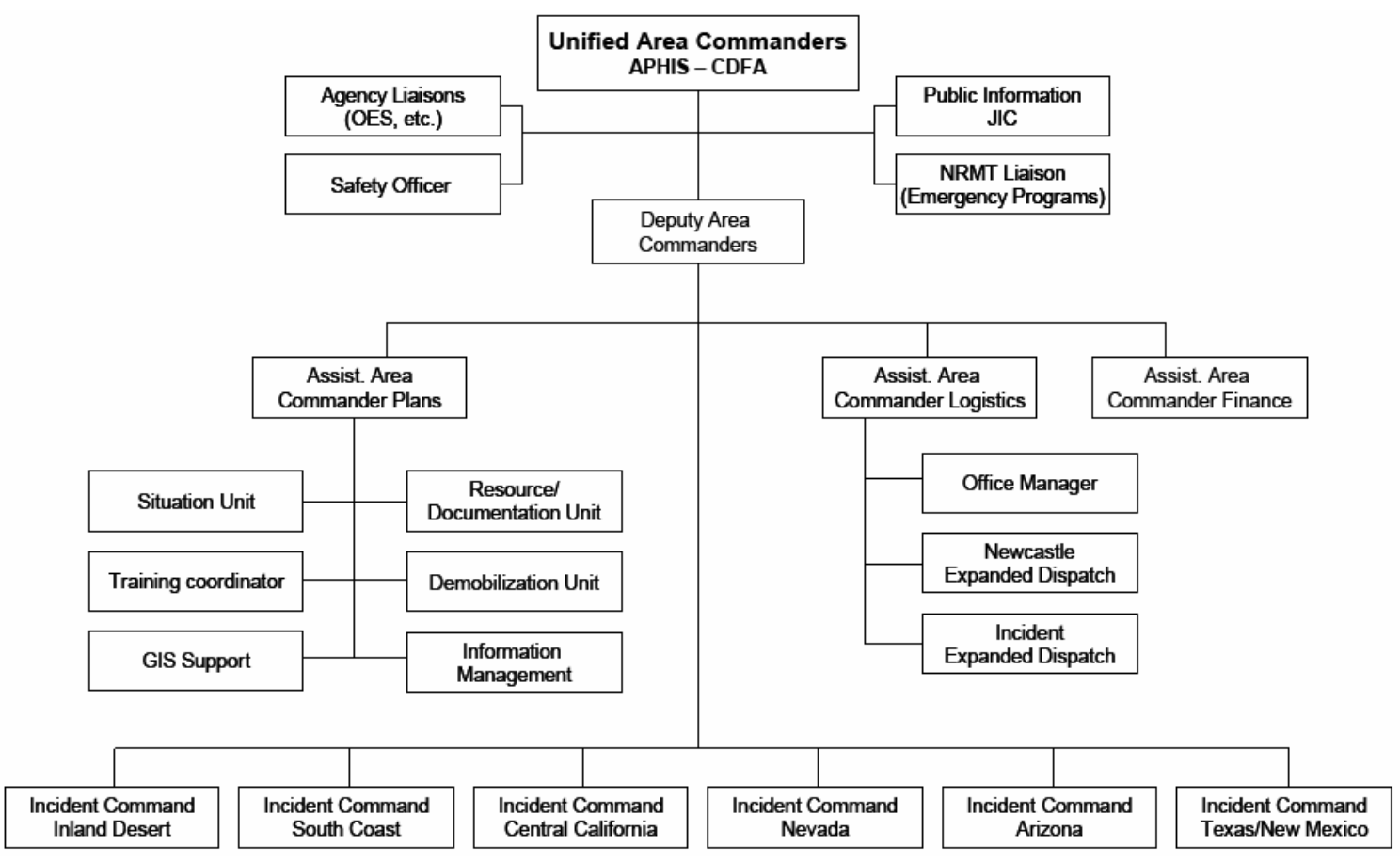




\begin{tabular}{|c|c|}
\hline \multicolumn{2}{|c|}{ Appendix 1: Main Network Participants and Skills } \\
\hline Agency & Skill \\
\hline $\begin{array}{l}\text { Animal Health and Food Safety } \\
\text { Services (part of California } \\
\text { Department of Food and } \\
\text { Agriculture) }\end{array}$ & $\begin{array}{l}\text { - } \text { Veterinary expertise } \\
\text { - } \text { Understanding of END; how to identify disease, cleaning and disinfectant } \\
\text { procedures } \\
\text { - } \quad \text { Local knowledge } \\
\text { Preplanning for animal disease response in California }\end{array}$ \\
\hline $\begin{array}{l}\text { Veterinary Services (part of } \\
\text { APHIS, part of USDA) }\end{array}$ & 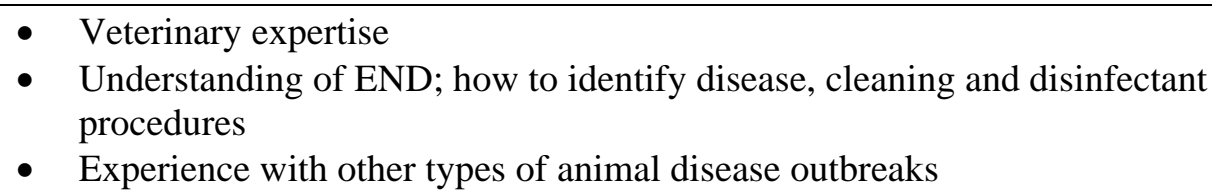 \\
\hline $\begin{array}{l}\text { California Department of } \\
\text { Forestry and Fire Prevention } \\
\text { US Forest Service (part of } \\
\text { USDA) }\end{array}$ & $\begin{array}{l}\text { - } \quad \text { Experience with applying ICS in emergency situations } \\
\text { - } \quad \text { Hiring flexibility } \\
\text { - } \quad \text { Expertise on emergency logistics } \\
\text { - Experience in training and managing large number of emergency workers } \\
\text { - }\end{array}$ \\
\hline Office of Emergency Services & $\begin{array}{l}\text { - Awareness of the emergency resources available in different parts of the } \\
\text { California state government } \\
\text { - Authority to coordinate the actions of state agencies toward emergency } \\
\text { response } \\
\text { - Preplanning for animal disease response in California }\end{array}$ \\
\hline Temp agencies & $\begin{array}{ll}\text { - } & \text { Personnel management of temporary workers } \\
\text { - } & \text { Hiring flexibility }\end{array}$ \\
\hline Temporary employees & $\begin{array}{ll}\text { - } & \text { Volume of work support } \\
\text { - } & \text { Continuity at frontlines } \\
\text { - } & \text { Knowledge of local environment, language and customs }\end{array}$ \\
\hline $\begin{array}{l}\text { California Animal Health and } \\
\text { Food Safety Lab and National } \\
\text { Veterinary Services Laboratory }\end{array}$ & $\begin{array}{ll}\text { - } & \text { Ability to identify disease } \\
\text { - } & \text { Development of rapid diagnostic test }\end{array}$ \\
\hline $\begin{array}{l}\text { National Response } \\
\text { Management Team (NMRT, } \\
\text { part of USDA) }\end{array}$ & $\begin{array}{l}\text { - } \text { Coordination of federal agencies } \\
\text { - Develop interagency cooperation agreements with other USDA agencies } \\
\text { - Develop financial requests and reports for US Office of Management and } \\
\text { Budget }\end{array}$ \\
\hline California Highway Patrol & $\begin{array}{l}\text { - Ability to enforce quarantine: created checkpoints at weigh stations to } \\
\text { ensure that commercial vehicles observing quarantine; inspected trucks } \\
\text { stopped for routine traffic violations }\end{array}$ \\
\hline $\begin{array}{l}\text { California Environmental } \\
\text { Protection Agency }\end{array}$ & - Understanding of disposal and decontamination procedures \\
\hline $\begin{array}{l}\text { California Department of } \\
\text { Health Services }\end{array}$ & $\begin{array}{l}\text { - Understanding of health risk to humans } \\
\text { - Understanding of risk communication to the public }\end{array}$ \\
\hline
\end{tabular}




\section{References}

9/11 Commission Report. 2004. Final Report of the National Commission on Terrorist Attacks Upon the United States, Official Government Edition. Washington D.C.: Government Printing Office.

Agranoff, Robert and Michael McGuire. 2001. Big Questions in Public Management Network Research. Journal of Public Administration and Research Theory 11(3): 295-326.

Alter, Catherine and Jerald Hage. 1992. Organizations Working Together: Coordination of Interorganizational Networks. Beverly Hills, CA: Sage.

Bardach, Eugene. 1998. Getting Agencies to Work Together. Washington D.C.: Brookings Institution.

Bardach, Eugene. 2001. Developmental Dynamics: Interagency Collaboration as an Emergent Phenomenon. Journal of Public Administration Research and Theory 11(1): 149-164.

Brass, Daniel J., Joseph Galaskiewicz, Henrich R. Greve, and Wenpon Tsai. 2004. Taking Stock of Networks and Organizations: A Multilevel Perspective. Academy of Management Journal. 47(8): 795-817.

California Department of Food and Agriculture (CDFA). 2002. Mobilization Plan for Emergency Animal Disease of Livestock. Unpublished document.

Cook, Alethia. 2005. Evaluating Emergency Response to a Terrorist Attack: Making the Most of Expert Interviews. Prepared for delivery at the 2005 Annual Meeting of the American Political Science Association Washington, DC, August 20 - September 4, 2005.

Comfort, Louise K. 2005. Rethinking Security: Organizational Fragility in Extreme Events. Public Administration Review. 2002: 62 (Special Issue): 98-107.

Comfort, Louise K. 2005. Asymmetric Information Processes in Extreme Events: The 26 December Sumatran Earthquake and Tsunami. Paper presented at the International Public Management Network Workshop on Communicable Crises: Prevent, Management and Resolution in an Era of Globalization, University of British Columbia, Canada, August 15-18.

Gerberding, Julie. 2004. Webb Lecture. National Academy of Public Administration Fall Meeting, November 18.

Goldsmith, Stephen and William D. Eggers. 2004. Government by Network: The New Shape of the Public Sector. Washington DC: The Brookings Institution.

Falkenrath, Richard. 2005. Homeland Security and Consequence Management. 131-138. http://www.brookings.edu/views/articles/falkenrath/2005_aspen.pdf 
Howell, Barry. 2004. Analysis of Response Operations to Eradicate Exotic Newcastle Disease in 2002-2003: Response Management. Alexandria, VA: The CNA Corporation.

Howell, Barry, Michael Webb, Matthew Grund, Christine Hughes, Elizabeth Myrus, Joel Silverman, and Rosemary Speers. 2004. Timeline of Response Operations to Eradicate Exotic Newcastle Disease in 2002-03. Alexandria, VA: The CNA Corporation.

Koppenjan, Joop, and Hans-Erik Klijn. 2004. Managing Uncertainties in Networks : A Network Approach to Problem Solving and Decision Making. New York, NY: Routledge.

Long, Norton E. 1949. Politics and Administration. Public Administration Review 9(4): 257264.

Lipton, Eric, Christopher Drew, Scott Shane and David Rohde. 2005. Breakdowns Marked from Hurricane to Anarchy. The New York Times, September 11, A1.

McGuire, Michael. 2003. Is it Really So Strange? A Critical Look at the "Network Management is Different from Hierarchical Management" Perspective. Paper presented at the $7^{\text {th }}$ Public Management Research Conference, Georgetown University, Washington, D.C., October 9-11.

Milward, H. Brinton and Keith G. Provan. 2000. Governing the Hollow State. Journal of Public Administration and Research Theory 10(4): 359-380.

Moynihan, Donald P. 2005a. "Homeland Security and the U.S. Public Management Policy Agenda." Governance: An International Journal of Policy, Administration and Institutions 18(2): 171-196.

Moynihan, Donald P. 2005b. Leveraging Collaborative Networks in Infrequent Emergency Situations. Report to the IBM Center for the Business of Government. http://www.businessofgovernment.com/pdfs/MoynihanReport.pdf

Moynihan, Donald P. and Pamela Herd. 2005. Joining-up Government in Emergency Situations: How Agencies Work Together When Everything Falls Apart? Paper presented at the Ninth International Research Symposium on Public Management (IRSPM IX), Bocconi University, Milan, Italy, April 6-8.

Ostrom, Elinor. 1998. A Behavioral Approach to the Rational Choice Theory of Collective Action. American Political Science Review 92: 1-22.

O’ Toole, Laurence J., Jr. 1997. “Treating Networks Seriously: Practical and Research-Based Agendas in Public Administration.” Public Administration Review 57 (1): 45-52.

O’ Toole, Laurence, Jr and Kenneth J. Meier. 1999. Modeling the Impact of Public Management: Implications of Structural Context. Journal of Public Administration Research and Theory 9(4): 505-526. 
Powell, Walter W. 1990. Neither Market Nor Hierarchy: Network Forms of Organization. Research in Organizational Behavior 12: 295-336.

Provan, Keith G. and H. Brinton Milward, "Institutional-Level Norms and Organizational Involvement In a Service-Implementation Network,” Journal of Public Administration Research and Theory (1991): 391-417

Schein, Edgar. 1992. Organizational Culture and Leadership, $2^{\text {nd }}$ ed. San Francisco, CA: Jossey Bass.

Speers, Rosemary and Michael Webb. 2004. Analysis of Response Operations to Eradicate Exotic Newcastle Disease in 2002-03: Outbreak Data and Case Reporting. Alexandria, VS: The CNA Corporation.

Speers, Rosemary, Michael Webb, Matthew Grund, Barry Howell, Christine Hughes, Elizabeth Myrus, and Joel Silverman. 2004. Reconstruction of Response Operations to Eradicate Exotic Newcastle Disease in 2002-2003. Alexandria, VA: The CNA Corporation.

U.S. Department of Homeland Security (DHS). 2004a. National Incident Management System. Washington D.C.: Government Printing Office. Available online at: http://www.dhs.gov/interweb/assetlibrary/NIMS-90-web.pdf.

U.S. Department of Homeland Security (DHS). 2004b. National Response Plan. Washington D.C.: Government Printing Office. Available online at: http://www.dhs.gov/interweb/assetlibrary/NRPbaseplan.pdf.

Werge, Rob W. 2004. Exotic Newcastle Disease After Action Review. Fort Collins, CO: Policy and Program Development, APHIS.

Weick, Karl. 1995. Sensemaking in Organizations. Thousand Oaks, CA: Sage.

Zaheer, Akbar, Bill McEvily and Vincenzo Perrone. 1998. Does Trust Matter? Exploring the Effects of Interorganizational and Interpersonal Trust on Performance. Organization Science 9(2): 141-159. 


\section{Endnotes}

i The original quote reads: "the lifeblood of administration is power" (Long, 1949, 257).

ii The NIMS document states that the policy it promotes are based on best practice and the experience of emergency response teams through extensive consultation, and does not refer to management theories as a source domain for ideas. To the extent that theory is implied, references to unified command and span of control suggest PODSCORB-era public administration principles. If we are to accept the claims of the NIMS document, we may therefore classify hierarchical networks as a concept borne from practice rather than theory.

iii The center attempted to make key decisions on where to go, and what to do for them. In alternative emergencies where there is greater ambiguity about technology and a less coherent response, such a centralized use of information might prove counter-productive, as Comfort (2005) demonstrates in the Tsunami crisis.

iv The NIMS also calls for standardization of some basic procedures. For resource management, NIMS called for standardized "requirements for processes to describe, inventory, mobilize, dispatch, track and recover resources over the life cycle of an incident" (DHS, 2004, 5).

${ }^{\mathrm{v}}$ The final manual covered all aspects of the taskforce work, including vehicle use, reporting accidents and injuries, policy on media contacts, and policy on overtime. Under finance, the manual covered processing purchase orders, processing indemnity claims, and budget reconciliation. There were mobilization and demobilization SOPs aimed to help orient employees. There was a section on personnel conduct and interacting with the public, and another section covered animal control, human health, pet bird protocols, biosecurity and safety, non-commercial site surveillance, commercial site surveillance, quarantine, diagnostics, epidemiology, regulatory enforcement in quarantines, disposal, euthanasia, cleaning and disinfection, movement and permitting, indemnity, sentinel birds, area quarantine release, and commercial poultry planning.

${ }^{\mathrm{vi}}$ The taskforce sought to reduce the impact of turnover by moving managers back into the same position, and rotating in and out entire teams of workers who were familiar with one another.

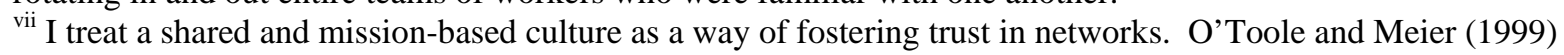
offers a slightly different view, arguing that shared and mutually reinforcing goals, and community norms foster system stability in networks.

viii The findings here are consistent with observations made by Agranoff and McGuire $(2001,314)$ on the role of leadership: "The leader as craftsman elicits common goals, creates an atmosphere of trust, brokers organizational and individual contributions, and deploys energies in accord with some strategic plan. It is important to note that these are not personal attributes, talents or conditions of individuals; they are roles in a system of strategic interaction.” Bardach $(1998,2001)$ has also pointed to the importance of leadership in collaboration in ways that are consistent with the experience of the END taskforce. "My research suggests the critical important of leadership to ICC [interagency collaborative capacity] success. Leadership can help an ICC define mission and goals.

Leadership is also, depending on the circumstances, a means for diagnosing and implementing improvements in the operating subsystem of the ICC, inducing resource contributions, nurturing an ethos of interpersonal trust and organizational pragmatism, executing a long-range developmental strategy, and diffusing expectations that ones own personal or agency efforts will be matched by the efforts of potential partners” $(2001,9)$. Bardach also notes that leadership can emerge in different ways. With the END taskforce leadership emerged because the structure formally required leaders and the dominant agencies filled these leadership roles.

ix The case evidence is consistent with previous findings. Zaheer, McEvily and Perrone (1998) point out that there is a difference between interpersonal trust between boundary spanners of organizations, and developing trust toward the organizational as a whole, but they also find that the former helps to generate the latter. 